\title{
Morphological Changes of the Intestinal Mucosa of Broilers and Layers as Affected by Fasting Before Sample Collection
}

\section{घAuthor(s)}

Zavarize $\mathrm{KC}$

Sartori JR

Gonzales E

Pezzato AC

UNESP - Botucatu Campus.

\section{Mail Adress}

KC Zavarize

Universidade Estadual de Goiás - UEG

Rua da Saudade esquina com Viela B, n56

Vila Eduarda

76.100-000. São Luís de Montes Belos, GO, Brasil

E-mail: kelen_zavarize@yahoo.com.br

\section{-Keywords}

Fasting, intestine, morphology, organs, strain.

\begin{abstract}
The present study aimed at evaluating the histo-morphological changes resulting from different fasting periods before the collection of tissue samples in different segments of the small intestine (duodenum, jejunum and ileum) of 7-d-old male chicks of a broiler and a layer strain. A completely randomized experimental design in in a $2 \times 7$ factorial arrangement, being two strains with different growth rates (Ross 308 and HyLine ${ }^{\circledR}$ W36) and seven fasting periods $(0,2,4,6,8,10$ and 12 hours ), with six replicates, totaling 84 birds. The comparison of the morphometrics of the duodenum, jejunum and ileum of broiler and layer chicks demonstrated faster digestive tract development in broilers relative to layers. The fasting period caused morphological changes in the liver and small and large intestines in both strains. Therefore, it must be highlighted that in studies involving organ weights and intestinal morphometrics, birds must not be submitted to fasting before tissue collection.
\end{abstract}

\section{INTRODUCTION}

The growth rate of broilers selected for fast growth is considerably influenced by intestinal development (Smith et al., 1990). After hatching, the small intestine of poultry grows faster, weight-wise, than total body mass. In broiler, small intestine relative growth reaches its peak between six and 10 days of age, independently of the presence of absence of food (Mateos et al., 2004; Sklan, 2004). However, feed intake stimulates the development of the gastrointestinal tract (GIT) (Gracia et al., 2003), and duodenum develops earlier than the jejunum and the ileum (Uni et al., 1999).

In broilers, the biochemical and morphological development, and consequent maturation of the small intestine, occur during the first 10 days of life. Villi area and size rapidly increase between one and two days of age, and then their growth rate gradually decreases, reaching a plateau between five and 10 days post-hatch (Uni et al., 1996). However, the proliferation of intestinal epithelial cells in broilers is not limited to the crypts; it also occurs along the villi during the first week of life (Uni et al., 1998a). The changes that occur in the intestine prepare the chicks to use the nutrients supplied by exogenous feeding (Uni et al., 1998b).

Fasting hatchlings for 24 hours negatively affects broiler performance at market age, and this is related mainly to its inadequate gastrointestinal tract development (Sklan, 2001; Gonzales et al., 2003). Therefore, due to the importance they have for the future performance of broilers, the first few hours and the first week of life of broilers chicks have been subject of many studies on the morphometrics of the gastrointestinal tract, particularly of the duodenum, jejunum and ileum in the small intestine (Macari et al., 2002). 
The current methods of morphometric evaluation of small intestine segments require fasting the birds for at least 12 hours before slaughter in order to reduce contamination risks and to promote complete emptying of the gastrointestinal tract. Fasting aims at preventing imprecisions, as the physical presence of feed particles in the intestinal lumen may cause structural destruction of the villi, resulting in incorrect morphometric measurements, and hence, imprecise evaluation. However, the intestinal epithelium is also affected by the absence of feed, as observed by Yamauchi et al. (1996), who found significant duodenal villi height reduction in broilers exposed to 24-h fasting.

During the first week of life - a critical development phase in the development of the newborn - the absence or presence of exogenous food changes the structure of villi in the intestinal mucosa both of mammals, such as rats (Ross \& Mayhew, 1984), and of poultry (Tarachai \& Yamauchi, 2000). However, the rate in which these changes occur is considerably different among animal species and classes: it is much faster in poultry, particularly in broilers selected for high growth rate and feed efficiency (Smith et al., 1990).

According to Sakamoto \& Yamauchi (2000), three hours after re-feeding of chicks submitted to fasting is sufficient to observe clear changes in the small intestine villi structure, indicating the speed in which the gastrointestinal tract responds to the absence or presence of stimuli, reducing or increasing cell turnover. Tarachai \& Yamauchi (2000) also determine that the stimuli are mostly chemical, and not physical, as the structural changes result from the enteral absorption of nutrients.

Different studies evaluating the morphometric characteristics of the small intestine mucosa detected that fasting previous to tissue collection may impair the collection of data relative to observations not related with feed withdrawal. Therefore, fasting may influence the correct interpretation of experiments evaluating conditions that may affect the integrity and the morphology of the digestive tract.

The objective of the present study was to establish de maximum fasting period to which broiler and layer chicks may be submitted that does not cause morphological changes in different segments of the small intestine (duodenum, jejunum, and ileum) as well as in other organs.

\section{MATERIALS AND METHODS}

The experiment was carried out at the Poultry
Nutrition Laboratory of the School of Veterinary Medicine and Animal Science of UNESP, Botucatu campus.

A total of 120 one-day-old male chicks, being 60 Ross $^{\circledR} 308$ broilers and 60 HyLine ${ }^{\circledR}$ W36 layers, was used. Chicks were vaccinated in the hatchery against Marek's disease.

Chicks were housed in 12 battery divisions, each being $0.30 \mathrm{~m}$ high, $0.95 \mathrm{~m}$ wide, and $0.50 \mathrm{~m}$ deep, located in the two central levels of a four-level battery. Ten randomly-distributed chicks from the same strain were housed in each division.

Chicks were brooded using 250-W infrared lamps, one per division. Water and feed were supplied ad libitum in two nipple drinkers and a trough feeder per division.

Birds were distributed according to a completely randomized experimental design in a $2 \times 7$ factorial arrangement, being two strains with different growth rates (Ross ${ }^{\circledR} 308$ and HyLine ${ }^{\circledR}$ W36) and seven fasting periods $(0,2,4,6,8,10$ and 12 hours ), with six replicates each. Feed was based on corn and soybean meal, and was formulated according to the recommendations of Rostagno et al. (2005).

When birds were seven days of age, feed supply was interrupted, and at every two hours, until 12 hours of fasting were completed, one bird per replicate was sacrificed by neck dislocation, totaling 84 birds, representing seven collection periods $\times 12$ birds (six broilers and six layers).

In order to evaluate organ weights and intestinal morphometrics, the heart, gizzard, proventriculus, liver, pancreas, small intestine and the large intestine, including the ceca, were collected and weighed immediately after collection. The gizzard was opened and weighed after its content was removed. After removal, the small and large intestines were cut in segments, weighed and measured The small intestine was measured between from the site where the duodenum emerges from the gizzard and the beginning of the ceca, and the large intestine length included the length of the colon and the rectum, adding the length of the ceca. Organ relative weight was calculated relative to live body weight. Chicks were weighed before sacrifice.

Two segments measuring approximately $3.0 \mathrm{~cm}$ of the duodenum, jejunum and ileum were cross sectioned and longitudinally opened by the mesenteric edge. Samples were washed in phosphate buffer solution at $0.1 \mathrm{M}(\mathrm{pH} 7.4)$ and fixed in Bouin solution for three days. Samples were then trimmed to eliminate the torn 
edges, and remained for further 24 hours in the fixing solution. Samples were then washed in ethanol at $70 \%$ to remove the fixing solutions, dehydrated in graded series of alcohol, cleared in xylol, and embedded in "paraplast". Four semi-serial sections with 7-m thickness were placed in each slide. Slides were died using the method of the periodic acid of Schiff (PAS).

Using an image capture and analysis system (ImagePro Plus version 4.5, 0.27), villi height and perimeter and crypt depth were measured and goblet cells were counted in duodenum, jejunum and ileum sections. Villus height was measured from the basal region, which starts at the higher portion of the crypts, until villus tip, whereas crypt depth was measure from the base up to the crypt-villi transition region (Carrijo et al., 2005). Perimeter was measured around the border where microvilli were located (Uni et al., 1995). Goblet cell number and goblet cell:epithelial cell ratio were determined by counting 500 epithelial cells and all goblet cells per slide.

The obtained results were submitted to analysis of variance (ANOVA), using the GLM procedure of SAS statistical software (1996).

\section{RESULTS AND DISCUSSION}

There was no significant interaction between fasting period and bird strain regarding organ weight and intestinal length (Table 1) or any influence of fasting period on gizzard, proventriculus or pancreas relative weights. Fasting period reduced the relative weights of the liver, small intestine and large intestine $(p<0.01)$. The relative weights of the liver and large intestine linearly decreased $(p<0.01)$ with fasting period, and are expressed by the following: Liver $(\%)=4.63-0.08$ $x$ Fasting $\left(R^{2}=0.31\right)$ and $\mathrm{LI}(\%)=1.81-0.05 x$ Fasting $\left(R^{2}=0.28\right)$, respectively. The change in relative small intestine weight as a function of fasting period was quadratic and is expressed by the equation $\mathrm{SI}(\%)=$ $9.34-0.69 \times$ Fasting $+0.04 \times$ Fasting $2\left(R^{2}=0.60\right)$.

Large intestine length linearly decreased $(p<0.01)$ as a function of fasting period and it is expressed by the equation: $\mathrm{LI}(\mathrm{cm})=17.48-0.24 \times$ Fasting $\left(R^{2}=0.15\right)$. These results are consistent with those obtained by Gonzales et al. (2003), who observed that fasting periods of 18 and 36 hours reduced the relative weight of the small intestine in broiler chicks. However, those authors also observed a reduction in small intestine length, which was not the case in the present experiment.

Strain affected the relative weights of the gizzard, pancreas and large intestine, with higher values $(p<$ 0.01) obtained in layer chicks compared with broiler chicks, which, in turn, presented longer small and large intestines $(p<0.01)$.

There was no interaction between fasting period and strain for villus perimeter, crypt depth and goblet cells/epithelial cells ratio in the duodenum, jejunum and ileum (Table 2). Fasting linearly increased $(p<0.01)$ goblet cells/epithelial cells ratio in the jejunum, which is expressed by the equation: $\mathrm{G} / \mathrm{E}=30.12+0.36 \mathrm{x}$ Fasting $\left(R^{2}=0.09\right)$, indicating the defense adaptation

Table 1 - Relative organ weight* (\%) and intestinal length $(\mathrm{cm})$ of seven-day-old chicks as a function of fasting period and strain.

\begin{tabular}{|c|c|c|c|c|c|c|c|c|}
\hline & \multicolumn{2}{|c|}{ Relative weight. \% } & \multicolumn{4}{|c|}{ Length. $\mathrm{cm}$} & \multirow{2}{*}{ Small intestine } & \multirow{2}{*}{ Large intestine } \\
\hline & Gizzard & Proventr. & Liver & Pancreas & Small intestine & Large intestine & & \\
\hline Fasting (F) & ns & ns & $p<0.01$ & ns & $p<0.01$ & $p<0.01$ & ns & $p<0.01$ \\
\hline 0 & 4.98 & 1.12 & $4.79 a$ & 0.61 & $9.51 a$ & $1.71 \mathrm{ab}$ & 76.6 & $17.3 a$ \\
\hline 2 & 5.47 & 1.14 & $4.49 a b$ & 0.60 & $7.90 \mathrm{~b}$ & $1.81 a$ & 74.2 & $17.4 a$ \\
\hline 4 & 5.36 & 1.21 & $4.16 \mathrm{bc}$ & 0.58 & $7.04 c$ & $1.57 a b c$ & 70.5 & $16.4 a$ \\
\hline 6 & 5.27 & 1.13 & $3.98 \mathrm{c}$ & 0.59 & $6.56 c$ & $1.49 \mathrm{cb}$ & 70.6 & $15.8 \mathrm{ba}$ \\
\hline 8 & 5.17 & 1.16 & $4.09 \mathrm{bc}$ & 0.65 & $6.35 c$ & $1.29 \mathrm{~cd}$ & 74.6 & $16.5 a$ \\
\hline 10 & 5.28 & 1.11 & $3.95 c$ & 0.60 & $6.33 c$ & $1.34 c d$ & 71.2 & $14.6 b$ \\
\hline 12 & 5.39 & 1.23 & $3.76 \mathrm{c}$ & 0.55 & $6.32 c$ & $1.18 d$ & 70.5 & $14.5 b$ \\
\hline Strain (S) & $p<0.01$ & ns & ns & $p<0.01$ & ns & $p<0.01$ & $p<0.01$ & $p<0.01$ \\
\hline Broiler & $5.10 \mathrm{~B}$ & 1.13 & 4.18 & $0.53 B$ & 7.14 & $1.29 \mathrm{~B}$ & $82.8 \mathrm{~A}$ & $17.8 \mathrm{~A}$ \\
\hline Layer & $5.44 \mathrm{~A}$ & 1.18 & 4.16 & $0.66 \mathrm{~A}$ & 7.15 & $1.69 \mathrm{~A}$ & $62.4 \mathrm{~B}$ & $14.4 \mathrm{~B}$ \\
\hline Interaction (FxS) & ns & ns & ns & ns & ns & ns & ns & ns \\
\hline CV (\%) & 7.8 & 11.5 & 11.1 & 20.2 & 13.3 & 18.8 & 7.4 & 9.1 \\
\hline
\end{tabular}

* Relative organ weight $(\%)=$ (organ weight live weight) $\times 100$. a,b,c Means in the same column followed by different small letters are significantly different by the SNK test. A,B Means in the same column followed by different capital letters are significantly different by the $F$ test. ns $=$ not significant. 
Table 2 - Villus perimeter (VP), crypt depth (CD), and goblet cell:epitelial cell ratio (G/E) in the duodenum, jejunum and ileum, as a function of fasting period and strain.

\begin{tabular}{|c|c|c|c|c|c|c|c|c|c|}
\hline & \multicolumn{3}{|c|}{ Duodenum } & \multicolumn{3}{|c|}{ Jejunum } & \multicolumn{3}{|c|}{ Ileum } \\
\hline & VP. $m$ & CD. $\mathrm{m}$ & $\mathrm{G} / \mathrm{E}^{1}$ & VP. $m$ & CD. $\mathrm{m}$ & $G / E^{1}$ & VP. $m$ & CD. $m$ & $G / E^{1}$ \\
\hline Fasting (F) & ns & ns & ns & ns & ns & $p<0.01$ & $p<0.05$ & ns & ns \\
\hline 0 & 1989 & 108 & 25 & 1003 & 87 & $29 b$ & $681 b$ & 71 & 38 \\
\hline 2 & 2015 & 101 & 25 & 1010 & 83 & $31 a b$ & $703 a b$ & 73 & 38 \\
\hline 4 & 2035 & 107 & 27 & 1072 & 94 & $32 a b$ & $761 a b$ & 73 & 40 \\
\hline 6 & 1976 & 98 & 26 & 1061 & 86 & $34 a$ & $797 a b$ & 78 & 40 \\
\hline 8 & 1983 & 104 & 25 & 1187 & 95 & $32 a b$ & $808 a$ & 78 & 38 \\
\hline 10 & 1813 & 99 & 27 & 1034 & 91 & $32 a b$ & 714ab & 72 & 39 \\
\hline 12 & 1920 & 102 & 29 & 1214 & 89 & $35 a$ & $732 a b$ & 77 & 40 \\
\hline Strain (S) & $p<0.01$ & ns & ns & $p<0.01$ & $p<0.05$ & $p<0.01$ & $p<0.01$ & ns & $p<0.01$ \\
\hline Broiler & $2065 A$ & 103 & 27 & $1168 \mathrm{~A}$ & $93 \mathrm{~A}$ & $35 \mathrm{~A}$ & $801 \mathrm{~A}$ & 76 & $42 \mathrm{~A}$ \\
\hline Layer & $1853 \mathrm{~B}$ & 102 & 26 & $1001 \mathrm{~B}$ & $85 B$ & $30 \mathrm{~B}$ & $686 B$ & 73 & $36 \mathrm{~B}$ \\
\hline Interaction (FxS) & ns & ns & ns & ns & ns & ns & ns & ns & ns \\
\hline CV $(\%)$ & 14.7 & 13.6 & 15.1 & 16.4 & 14.9 & 12.3 & 13.6 & 16.1 & 11.0 \\
\hline
\end{tabular}

1 - Count of 500 epithelial cells and all goblet cells per bird. a,b,c - Means in the same column followed by different small letters are significantly different by the SNK test. A,B - Means in the same column followed by different capital letters are significantly different by the $\mathrm{F}$ test. ns = not significant.

of the intestinal mucosa to fasting. Fasting period also promoted a quadratic increase $(p<0.01)$ in villus perimeter in the ileum, expressed by the equation: $\mathrm{VP}=$ $669.86+33.60 \times$ Fasting $-2.46 \times$ Fasting $^{2}\left(R^{2}=0.10\right)$. However, the low $R^{2}$ value indicates that this increase in villus perimeter is not closely related to fasting period. There was no effect of fasting on villus perimeter in the duodenum or in the jejunum. These results are different from the findings of Yamauchi et al. (1996) and Gonzales et al. (2003), who observed that up to 18 hours of fasting immediately after hatch reduced villi height and crypt depth in the duodenum, jejunum and ileum of broiler chicks. Those authors suggest that these changes may affect the performance of broilers at 42 days of age. However, it should be considered the those authors worked with broiler chicks up to 48 hours after hatch and with longer fasting periods than those applied in the present experiment.

Shakamoto \& Yamauchi (2000) reported that changes in villi height and enterocyte area can be observed submitted to fasting during post-hatching phase, and that these changes can be used to estimate intestinal function and their negative effect on body weight gain.

The remaining evaluated characteristics of the different small intestine segments were not affected by fasting period $(p>0.05)$. Broiler chicks presented higher $(p<0.01)$ villus perimeter in the duodenum, jejunum and ileum compared with the layer chicks. In addition higher $(p<0.05)$ crypt depth values in the jejunum and goblet cells to epithelial cells ratio values were determined in the jejunum and ileum ( $p$ $<0.01$ ) of broiler chicks relative to layer chicks (Table 2). Consistent with the data presented by Macari et al. (2002), these results demonstrates the broiler and layer strains present different intestinal mucosa development rates: broilers have larger villi and deeper crypts, which may favor their higher body weight gain.

\section{CONCLUSIONS}

When the morphometrics of the duodenum, jejunum and ileum of broilers and layers the pre-starter growth phase, i.e., from hatch to seven days of age, was compared, the faster development of the intestinal tract of broilers relative to layers was evidenced. Fasting period promoted liver weight and small and large intestine morphological changes both in broilers and layers. Fasting birds before tissue collection in studies involving organ weight and intestinal morphometrics is not recommended.

\section{REFERERENCES}

Carrijo AS, Madeira LA, Sartori J, Pezzato AC, Gonçalves JC, Cruz VC, Kuibida K, Pinheiro DF. Alho em pó na alimentação alternativa de frangos de corte. Pesquisa Agropecuária Brasileira 2005; 40(7):673679.

Gracia Ml, Araníbar MJ, Lázaro R, Medel P, Mateos GG. Amylase supplementation of broiler diets based on corn. Poultry Science, 82 (3):436-442

Gonzales E, Kondo N, Saldanha ESP, Loddi M, Careghi C, Decuypere E. Performance and physiological parameters of broiler chickens subjected 
to fasting on the neonatal period. Poultry Science 2002, 82(8):12501256.

Mateos GG, Gonzáles-Alvarado JM, Lázaro R. Facing the realities of poultry health and performance without antibiotics in Europe. Proceedings of International Feed Industry Symposium;2004; Lexington. USA. p.6979 .

Macari M, Furlan RL, Gonzales E. Fisiologia aplicada a frango de corte. 2ed. Jaboticabal: Funep,Unesp; 2002. 375p.

Ross GA, Mayhew TM. Effects of fasting in villi along the small intestine: a stereological approach to the problem of quantifying villus shape. Experientiae 1984; 40(8):856-858

Rostagno HS, Albino LFT, Donzele JL, Gomes PC, Oliveira RF, Lopes DC, Ferreira AS, Barreto SLT. Tabelas brasileiras para aves e suínos: composição de alimentos e exigências nutricionais. Viçosa: UFV; 2005.

Sakamoto E,Yamauchi E. Recovery responses of chick intestinal villus morphology to different reffeding procedures. Poultry Science 2000; 79:718-723.

SAS Institut. SAS/STAT. User's guide, version 6.11. 4ed. Carry; 1996.

Sklan D. Development of digestive and absorptive functions in the intestine of poultry [CD-ROM]. Proceedings of World's Poultry Congress; 2004; Istambul. Turquia.

Sklan D. Development of the digestive tract of poultry. World's Poultry Science Journal 2001; 57(4):416-428.

Smith MW, Mithcell MA, Peacock MA. Effects of genetic selection on growth rate and intestinal structure in the domestic fowl (Gallus domesticus). Comparative Biochemistry Physiololgy 11990; 97A:57-63.

Tarachai F,Yamauchi E. Effects of luminal nutrient absortion, intraluminal physical stimulation, and intravenous parenteral alimentation on the recovery responses of duodenal villus morphology following feed withdrawal in chickens. Poultry Science 2000; 79:1578-1585.

Uni Z, Ganot S, Sklan D. Post-hatch development of mucosal function in the broiler small intestine. Poultry Science 1998a; 77:75-82.

Uni Z, Noy Y, Sklan D. Post hatch changes in morphology and function of small intestines in heavy ans light strain chicks. Poultry Science 1995; 74:1622-1629.

Uni Z, Noy Y, Sklan D. Developmental parameters of the small intestine in heavy and light strain chicks pre and post-hatch. British Poultry Science 1996; 36:63-71.

Uni Z, Platin R, Sklan D. Cell proliferation in chicken intestinal epithelium occurs both in the cript and along the villi. Journal Compomparative Physiology 1998b; 168:241-247.

Uni Z, Noy Y, Sklan D. Posthatch development of small intestinal function in the poult. Poultry Science 1999; 78(2):215-222.

Yamauchi $\mathrm{K}$, Kamisoyama $\mathrm{H}$, Isshiki Y. Effects of fasting and refeeding on structures of the intestinal villi and epithelial cells in White Leghorn hens. British Poultry Science 1996; 37:909-921. 